\title{
Speech intelligibility and childhood verbal apraxia in children with Down syndrome
}

\author{
Libby Kumin, Ph.D., CCC-SLP \\ Professor of Speech-Language Pathology \\ Loyola College in Maryland
}

\begin{abstract}
Many children with Down syndrome have difficulty with speech intelligibility. The present study used a parent survey to learn more about a specific factor that affects speech intelligibility, i.e. childhood verbal apraxia. One of the factors that affects speech intelligibility for children with Down syndrome is difficulty with voluntarily programming, combining, organising, and sequencing the movements necessary for speech. Historically, this difficulty, childhood verbal apraxia, has not been identified or treated in children with Down syndrome but recent research has documented that symptoms of childhood verbal apraxia can be found in children with Down syndrome. The survey examined whether and to what extent childhood verbal apraxia is currently being identified and treated in children with Down syndrome. The survey then asked parents to identify certain speech characteristics that occur always, frequently, sometimes or never in their child's everyday speech. There were 1620 surveys received. Survey results indicated that approximately $15 \%$ of the parents responding to the survey had been told that their child has childhood verbal apraxia. Examination of the everyday speech characteristics identified by the parents indicated that many more children are showing clinical symptoms of childhood verbal apraxia although they have not been given that diagnosis. The most common characteristics displayed by the subjects included decreased intelligibility with increased length of utterance, inconsistency of speech errors, difficulty sequencing oral movements and sounds, and a pattern of receptive language superior to expressive language. The survey also examined the impact of childhood verbal apraxia on speech intelligibility. Results indicated that children with Down syndrome who have clinical symptoms of childhood verbal apraxia have more difficulty with speech intelligibility, i.e. there was a significant correlation between childhood verbal apraxia and parental intelligibility ratings. Children with apraxia often do not begin to speak until after age 5 . There was a significant correlation between speech intelligibility and age at which the child began to speak, i.e. children who began to speak after age 5 had lower parental intelligibility ratings. A diagnosis of difficulty with oral motor skills is more frequently given than a diagnosis of apraxia; $60.2 \%$ of parents had been given this diagnosis. According to survey results, it is rare (2\%) for a diagnosis of childhood verbal apraxia to be made without a diagnosis of difficulty with oral motor skills.
\end{abstract}

Keywords: Down syndrome, speech intelligibility, speech, childhood verbal apraxia, developmental apraxia of speech, oral motor, communication, special needs

\section{Background information/need for the study}

Speech intelligibility has been defined as how clearly a person speaks so that his or her speech is comprehensible to a listener. (Leddy, 1999). Reduced speech intelligibility is a widespread problem for children with Down syndrome that has been documented in the literature in clinical case studies, surveys, and reports (Buckley, 2000; Chapman \& Hesketh, 2000; Chapman et al., 1998; Hesselwood et al., 1995; Horstmeier, 1988; Kumin, 1994, 2001, 2002a, 2002b; Miller \& Leddy, 1999, Rosin \& Swift, 1999; Swift \& Rosin, 1990, Stoel-Gammon, 2001). Parents are aware that speech intelligibility is a major problem for their children with Down syndrome. When 937 parents of children with Down syndrome were surveyed, over 95\% of the respondents reported that their children had difficulty being understood by people outside of their immediate circle sometimes or frequently. Only approximately $5 \%$ of parents reported that their children rarely or never had dif- 
ficulty in being understood (Kumin, 1994). Even when children with Down syndrome increase their expressive language skills, their effectiveness in communicating with others depends, to a large extent, on whether their speech can be understood (Chapman et al., 1998). For typically developing children, speech is usually $100 \%$ intelligible by four years of age (Coplan \& Gleason, 1988; Weiss et al., 1987). For children with Down syndrome, it appears to be unusual for speech to be $100 \%$ intelligible at any age.

Speech intelligibility is determined by individual factors and also by the interaction of these specific factors as they affect intelligibility for an individual (Kumin, 2001). For example, a child may have midface hypoplasia (underdeveloped mid front facial structures such as the bridge of the nose and the upper jaw) and an average sized tongue (anatomical), along with low muscle tone in the lips and tongue (physiological). The combination of these factors can result in articulation errors and reduced speech intelligibility because the child has difficulty making the precise movements for articulation, because the tongue has difficulty moving in the smaller oral space, because the tongue protrudes, and because of low muscle tone. In addition, research has found that there is a high incidence of conductive hearing loss in children with Down syndrome, related to fluid in the ear (glue ear), and that there is often difficulty with auditory discrimination skills. The hearing loss and auditory discrimination difficulties make it more difficult to hear the subtle differences between sounds, and therefore contribute to difficulty in producing speech sounds. Speech intelligibility can be rated globally in order to estimate the severity of the problem but it cannot be effectively treated globally (Kumin, 2001). A diagnosis of reduced speech intelligibility does not provide information that leads to appropriate treatment. The separate factors, e.g. weak oral motor skills or rapid rate of speech, need to be identified and treated in order to improve intelligibility overall. It is possible to separate out the specific factors that are affecting speech intelligibility for an individual, through a speech evaluation, so that those specific factors can be evaluated and treated (Kumin, 2003a, 2003b, 2002a, 2002b, 2001, 1994; Kumin \& Adams, 2000; Miller \& Leddy, 1999; Rosin \& Swift, 1999).

Two factors that can affect speech intelligibility are oral motor skills and oral motor planning skills (childhood verbal apraxia). Clinically, some children with Down syndrome demonstrate difficulties with oral motor skills, some demonstrate difficulties with oral motor planning, and some exhibit symptoms of both (Kumin, 2004, 2003a, 2003b, 2002a, 2002b, 2001; Kumin \& Adams, 2000). Although the presence of oral motor skill and oral motor planning skill impairments have been observed clinically, there is no information in the research literature on the incidence of problems with oral motor or motor planning skills in this population. Clinically, however, there is no doubt that, when present, they affect speech intelligibility. Numerous studies have examined the nature of difficulty with oral motor skills (Caruso \& Strand, 1999; Rosenfeld-Johnson, 1999; Square, 1999) and childhood verbal apraxia in typically developing children (Caruso \& Strand, 1999; Davis et al., 1998; Forrest, 2003; Hall et al., 1993; Nijland et al., 2003; Shriberg et al., 1997a; Shriberg et al., 1997b; Square, 1999; Strand \& McCauley, 1999; Strand \& Skinner, 1999; Williams et al., 1981). Oral motor skills refers to the strength and movement of oral facial muscles, especially the movements related to speech. Oral motor planning skills refers to the ability to combine and sequence sounds into words, phrases and sentences. Difficulty with oral motor planning skills is referred to as childhood verbal apraxia. Other terms have been used to describe this difficulty, include childhood verbal dyspraxia, developmental apraxia of speech, developmental dyspraxia, developmental verbal apraxia, articulatory dyspraxia, pediatric verbal apraxia, childhood apraxia of speech, and oral motor planning difficulties.

Childhood verbal apraxia is a description or a label, not a disease. It is defined by a cluster of clinical symptoms. In the research literature, the most frequently reported symptoms of childhood verbal apraxia in typically developing children are:

- inconsistency in phoneme (sound) production (Forrest, 2003; Hall et al., 1993; Shriberg et al., 1997a, Velleman, 2003)

- a decrease in intelligibility as utterance length increases (Edwards, 1973; Forrest, 2003; Hall et al.,1993; Strand \& Skinner, 1999)

- a limited repertoire of phonemes (Chappell, 1973; Edwards, 1973)

- preserved automatic phrases and movements, with more difficulty in imitation or spontaneous speech (Edwards, 1973; Shriberg et al.,1997a)

- difficulty combining and sequencing phonemes (Chappell, 1973; Forrest, 2003; Hall et al., 1993)

- phoneme and syllable reversals (i.e. metathesis) (Chappell, 1973; Edwards, 1973, Hall et al., 1993)

- struggle or groping on production of speech and/or non-speech tasks (Chappell, 1973; Edwards, 1973; Forrest, 2003; Shriberg et al., 1997a)

- speech rhythm difficulties (Edwards, 1973; Munson et al., 2003; Shriberg et al., 1997b; Velleman, 2003).

Some studies have cited difficulties with oral motor skills and feeding as usually accompanying childhood verbal apraxia (Forrest, 2003; Velleman, 2003) while other studies have not cited this relationship (Davis et al., 1998; Shriberg et al., 1997a, 1997b). Forrest (2003) surveyed 75 speechlanguage pathologists. He found that although they used over 50 different characteristics to establish a diagnosis of apraxia, six of the characteristics were cited by over $50 \%$ of the respondents. These characteristics were inconsistent productions, difficulty with oral motor skills, struggle and groping, difficulty with imitation of sounds, poor sound sequencing, and increasing difficulty with increased utterance length.

There has been very little research on either oral motor skills or childhood verbal apraxia in children with Down 
syndrome. Clinicians are beginning to identify difficulty with oral motor skills such as weak facial muscles in the facial area in children with Down syndrome. Speech-language pathology treatment manuals are beginning to suggest exercises and techniques to address oral motor problems (Chamberlain \& Strode, 1999; Oetter et al., 1995, Rosenfeld-Johnson, 1999). But, there have not been adequate descriptions of the oral motor difficulties. There also have not been studies of various treatment approaches for oral motor difficulties and their results. Childhood verbal apraxia appears to be rarely diagnosed and treated in children with Down syndrome. Historically, the original researchers who defined apraxia of speech in children only included subjects, in their studies, who had an absence of hearing loss, absence of muscle weakness, and IQ scores within the normal range. Children with Down syndrome were excluded from the studies because they did not meet the selection criteria. Since that time, the definitions of childhood verbal apraxia have not been generalised beyond the original subject groups. The result has been that assessment and treatment for childhood verbal apraxia has not been provided for children with Down syndrome.

Recent research has documented that symptoms of childhood verbal apraxia are found in children with Down syndrome. Kumin and Adams (2000) studied seven children with Down syndrome who were experiencing difficulties with speech intelligibility. They used The Apraxia Profile (Hickman, 1997) which is a published test of speech characteristics. They also analysed the results of a parent questionnaire, and analysed a conversational connected speech sample to determine whether the children showed the characteristics of childhood verbal apraxia. Results of The Apraxia Profile indicated that all subjects had test scores leading to a diagnosis of childhood verbal apraxia. Analysis of the parent questionnaire and the conversational sample also showed that all seven children demonstrated characteristics of childhood verbal apraxia. The most common characteristics displayed by the subjects included decreased intelligibility with increased length of utterance, inconsistency of speech errors, decreased ability to perform voluntary tasks as compared to automatic tasks, and difficulty sequencing oral movements and speech sounds (Kumin \& Adams, 2000). All of these clinical symptoms found in the seven children with Down syndrome are the same symptoms of childhood verbal apraxia cited in studies of typically developing children.

There is a paucity of information regarding the nature of difficulty with oral motor skills and oral motor planning skills in children with Down syndrome. As a result, existing methods to evaluate and treat these difficulties in typically developing children, are rarely being applied to help children with Down syndrome. There is no definitive test for childhood verbal apraxia, at this time. It cannot be diagnosed by a blood test or a CT scan. Current speech and language evaluation instruments are descriptive and rely heavily on analysing the child's speech and sound imitation skills. Often, a conversational speech sample is used. By the time that children with Down syndrome are able to have a longer conversation of 50 to 100 utterances so that you can perform language sample analyses, they are often in middle childhood or adolescence. At that point, valuable treatment time has been lost. Childhood verbal apraxia can also be identified by the clinical symptoms exhibited in the child's speech and language development, as well as their speech output (Velleman, 2003). The current study investigated whether characteristics of childhood verbal apraxia can be identified in children with Down syndrome through the use of a parent survey. This can help document the existence of childhood verbal apraxia in children with Down syndrome. It can also lead to different ways of screening and diagnosing childhood verbal apraxia in children with Down syndrome at an earlier age, so that appropriate treatment methods can be used early to help children develop the oral motor planning skills that they need for speech.

\section{Method}

A 40 item survey instrument was developed to survey parents of children with Down syndrome regarding their child's speech. Other studies have demonstrated that parents of children with Down syndrome are accurate reporters of their children's language characteristics (Camaioni et al., 1991, Dale, 1991; Kumin, Councill \& Goodman, 1998, 1999; Miller, 1987, 1988, 1992; , Miller et al., 1995a, Miller et al., 1995b).) Clinical experience and the research literature have documented that there are speech and oral motor characteristics that are typical of children with childhood verbal apraxia and the survey included questions that addressed each of the major characteristics cited in the literature including:

a) History of speech and language delays

b) Feeding difficulties in infancy (Kumin \& Bahr, 1999; Pinder \& Faherty, 1999; Velleman, 2003)

c) Early history of limited cooing, babbling and vocal play (Kumin \& Adams, 2000)

d) Inconsistent production of speech sounds (Hall et al., 1993; Shriberg et al., 1997a; Rosin \& Swift, 1999; Velleman, 2003)

e) Limited number of speech sounds in the child's speech (Hall et al., 1993; Velleman, 2003)

f) Struggle or groping when speaking (Chappell, 1973; Edwards, 1973; Shriberg et al., 1997a)

g) Decrease in intelligibility as word or sentence length increases (Edwards, 1973; Hall et al., 1993; Strand \& Skinner, 1999)

h) Failure to improve, even through extensive therapy (Prichard et al., 1979)

i) Difficulty combining and sequencing phonemes (Chappell, 1973; Hall et al., 1993; Velleman, 2003)

j) Difficulty producing consonant and vowel sounds

k) Omits sounds and syllables in speech

l) Difficulty saying unfamiliar words

m) Difficulty imitating words 
Parents were asked to respond to statements about their child's speech and language. For each statement on the survey, parents were asked to respond whether their child showed these characteristics always, frequently, sometimes or never. Examples of statements are:

"My child seems to be struggling so hard to say words and phrases."

"It is hard for my child to imitate a word that I say."

A copy of the complete survey is included in Appendix A. The data in the surveys were statistically analysed and each question as well as clusters of questions (symptoms of childhood verbal apraxia, speech intelligibility data) were analysed separately.

Wide distribution of the survey was desired, so that a large number of responses could be analysed. The Down syndrome community is a physi-virtual community (Lazar \& Preece, 2001), i.e. some families live in the same geographic area or are attending the same conference in a specific location at a specific time (physical community), whereas others are spread out geographically and can be reached only by mail or through e-mail or the world wide web (virtual community). Lazar (2006) suggests sending information about a survey to related newsgroups, bulletin boards or listserves, posting information on related websites, and distributing fliers (e.g., at conferences) to maximise the number of survey responses. To reach the physical and virtual segments of the Down syndrome community, information about participating in the survey was sent to parent support groups, and was posted on the websites of the National Down Syndrome Society, the National Down Syndrome Congress, and the Down Syndrome Online Advocacy Group. Some family support groups included information in their newsletters and their webpages. An active recruiting method (Lazar \& Preece, 2001; Lazar et al., 1999; Marcell \& Falls, 2001) was used to ensure wide distribution of the survey.

\section{Results}

There were 1620 surveys received and analysed. Parents completed the survey for their children with Down syndrome. Gender of the children in the survey was 55.1 percent male and 44.9 percent female. Age of children whose parents responded to the survey ranged from 1 year to 21 years; the mean age was 8.16 years.

Most parents responding to the survey indicated that their child used speech to communicate. Results of respondents indicated that 87 to 90 percent of children in the survey communicate primarily using speech. Other communication systems used to augment speech include sign language, communication boards, and electronic communication devices. Because some children were younger, or not yet speaking, certain questions were not answered by each parent so the numbers answering a specific question varied. The full data set of responses can be found in Table 1 .

Parent's ratings of speech intelligibility were correlated with whether they had received a diagnosis of oral motor skill difficulty or childhood verbal apraxia. Parents ratings

\begin{tabular}{|c|c|c|c|c|}
\hline & Never & Sometimes & Frequently & Always \\
\hline I. & 48 & 572 & 338 & 105 \\
\hline 2. & 19 & 237 & 422 & 385 \\
\hline 3. & 82 & 178 & 267 & 538 \\
\hline 4. & 30 & 284 & 450 & 297 \\
\hline 5. & 63 & 340 & 404 & 253 \\
\hline 6. & 144 & 407 & 327 & 180 \\
\hline 7. & 455 & 292 & 169 & 150 \\
\hline 8. & 438 & 315 & 191 & 121 \\
\hline 9. & 831 & 185 & 37 & 17 \\
\hline 10. & 660 & 316 & 61 & 33 \\
\hline II. & 148 & 326 & 237 & 354 \\
\hline 12. & 253 & 448 & 199 & 168 \\
\hline 13. & 65 & 175 & 246 & 576 \\
\hline 14. & 37 & 243 & 472 & 300 \\
\hline 15. & 201 & 451 & 300 & 105 \\
\hline 16. & 7I & 266 & 366 & 345 \\
\hline 17. & 539 & 296 & 146 & 79 \\
\hline 18. & 409 & $34 I$ & 187 & 113 \\
\hline 19. & 148 & 368 & 295 & 252 \\
\hline 20. & 161 & 385 & 287 & 228 \\
\hline 21. & 286 & 370 & 278 & $12 \mid$ \\
\hline 22. & 556 & 282 & 169 & 55 \\
\hline 23. & 568 & 329 & 112 & 66 \\
\hline 24. & 79 & 285 & 322 & 375 \\
\hline 25. & 68 & 199 & 312 & I7) \\
\hline 26. & 65 & 312 & 386 & 307 \\
\hline 27. & 196 & 414 & 276 & $|8|$ \\
\hline 28. & 318 & 403 & 248 & 78 \\
\hline 29. & 261 & 382 & 276 & $13 \mid$ \\
\hline 30. & 381 & 399 & 200 & 70 \\
\hline 31. & 100 & 350 & 428 & 180 \\
\hline 32. & 133 & 376 & 388 & 157 \\
\hline 33. & 583 & 270 & 138 & 55 \\
\hline 34. & 261 & 321 & 257 & 224 \\
\hline 35. & 143 & 547 & 257 & 126 \\
\hline 36. & 52 & $14 \mid$ & 361 & 507 \\
\hline 37. & 46 & 58 & 147 & 825 \\
\hline 38. & 195 & 416 & 325 & 126 \\
\hline 39. & 90 & $24 I$ & 303 & $4 I I$ \\
\hline 40. & 88 & 393 & 292 & 293 \\
\hline
\end{tabular}

Table I. Responses to Survey Questions

of the speech behaviours observed in their children in daily life were analysed, to determine whether children who had not been given these diagnostic labels were demonstrating clinical symptoms of childhood verbal apraxia. 


\begin{tabular}{|c|c|c|}
\hline Score & Frequency & Percentage \\
\hline 0 & 7 & .4 \\
\hline I & 103 & 6.6 \\
\hline 2 & 156 & 9.9 \\
\hline 3 & 179 & 11.4 \\
\hline 4 & 216 & 13.7 \\
\hline 5 & 267 & 17.0 \\
\hline 6 & 186 & 11.8 \\
\hline 7 & 231 & 14.7 \\
\hline 8 & 145 & 9.2 \\
\hline 9 & 59 & 3.8 \\
\hline 10 & 23 & 1.5 \\
\hline $\mathrm{N}:$ & Mean: & 4.97 \\
\hline Median: & Mode: & 5 \\
\hline
\end{tabular}

Table 2. Speech intelligibility ratings of parents of their child's speech ratings of their children. A Pearson correlation between gender and intelligibility ratings was significant at the .01 level (2-tailed). Girls had higher speech intelligibility ratings (easier to understand speech) than boys. A Pearson correlation between age and speech intelligibility ratings was significant at the .01 level (2-tailed). Older children had higher speech intelligibility ratings than younger children. See Table 3 for age and gender results.

\begin{tabular}{|lcc|}
\hline & & Speech intelligibility \\
Age & Pearson correlation (2 tailed) & $.340 * *$ \\
Gender & Pearson correlation (2 tailed) & $-.195^{* *}$ \\
\hline$* *$ Correlation is significant at the 0.01 level (2-tailed) &
\end{tabular}

Table 3. Relationship between age, gender and speech intelligibility ratings

\section{Oral motor skills}

Children with Down syndrome are currently being diagnosed with difficulty in oral motor skills.

Results indicated that 60.2 percent of parents had been given a diagnosis of oral motor difficulties in their children. When questions relating to oral motor skills were analysed, a similar percentage of children showed clinical symptoms characteristic of oral motor skill difficulty. Parents reported that their children had more difficulty with low muscle tone in infancy, but that the muscle tone had improved over time. Responses are reported as percentage of the respondents who indicated always, frequently, sometimes, or never.

Only $13.7 \%$ of parents indicated that their child did not have low muscle tone in infancy, and $23.4 \%$ indicated that their child does not currently have low tone.

\begin{tabular}{|l|l|l|l|l|}
\hline Question: & always & frequently & sometimes & never \\
\hline $\begin{array}{l}\text { My child had low } \\
\text { tone in the muscles } \\
\text { of the face (lips, } \\
\text { tongue and cheeks) } \\
\text { in infancy }\end{array}$ & $32.8 \%$ & $22.0 \%$ & $30.2 \%$ & $13.7 \%$ \\
\hline $\begin{array}{l}\text { My child currently } \\
\text { has low tone in the } \\
\text { muscles of the face } \\
\text { (lips, tongue and } \\
\text { cheeks) }\end{array}$ & $15.6 \%$ & $18.4 \%$ & $41.5 \%$ & $23.4 \%$ \\
\hline
\end{tabular}

\section{Childhood verbal apraxia}

Survey results indicated that 15 percent of children had a diagnosis of apraxia or dyspraxia. It was very rare for childhood verbal apraxia to be the sole speech diagnosis, i.e. it was found to co-occur with oral motor skill difficulty in $98 \%$ of the children. In only $2 \%$ was there a diagnosis of childhood verbal apraxia occurring without difficulty with oral motor skills. There was no significant correlation between age and childhood verbal apraxia. There was a significant correlation between gender and childhood verbal apraxia. Boys were reported to have more difficulty with apraxia than girls. See Table 4 for the results. Speech intelligibility was inversely correlated with apraxia. Children who had apraxia had lower speech intelligibility ratings. See Table 5 for the results.

\begin{tabular}{|llc|}
\hline \multirow{3}{*}{ Age } & Apraxia \\
& Pearson correlation & -.007 \\
& Significance & .826 \\
& & .093 \\
& Pearson correlation & .004 \\
\cline { 2 - 3 } & Significance & \\
\hline
\end{tabular}

Table 4. Relationship between apraxia, gender and age

\begin{tabular}{|llc|}
\hline \multirow{3}{*}{ Apraxia } & Speech intelligibility \\
& Pearson correlation & -.402 \\
& Significance & .0001 \\
\hline
\end{tabular}

Table 5. Relationship between speech intelligibility rating and apraxia

When responses to specific questions on the survey are tabulated, it becomes clear that more children show signs and symptoms of apraxia characteristics, who have not been given that diagnosis.

\section{Inconsistent speech production}

One of the characteristics typically noted on lists of characteristics of childhood verbal apraxia is inconsistent speech production. Three questions addressed consistency with the following results: 


\begin{tabular}{|l|l|l|l|l|}
\hline Question: & always & frequently & sometimes & never \\
\hline $\begin{array}{l}\text { My child makes the } \\
\text { same speech errors } \\
\text { consistently }\end{array}$ & $27.8 \%$ & $43.7 \%$ & $22.5 \%$ & $3.4 \%$ \\
\hline $\begin{array}{l}\text { Sometimes my child } \\
\text { can say a word, but } \\
\text { at other times, my } \\
\text { child has difficulty } \\
\text { saying the same } \\
\text { word }\end{array}$ & $9.7 \%$ & $27.8 \%$ & $41.8 \%$ & $18.6 \%$ \\
\hline $\begin{array}{l}\text { My child may } \\
\text { unexpectedly say } \\
\text { a word or phrase } \\
\text { perfectly, but then, } \\
\text { he/she can't repeat it }\end{array}$ & $11.7 \%$ & $30.1 \%$ & $38.6 \%$ & $18.1 \%$ \\
\hline
\end{tabular}

It is interesting to note that the responses to the questions relating to ability to produce a sound word or phrase correctly sometimes, but not at other times were very close. Yet, when parents were asked whether their child's speech errors are consistent, they responded that they were consistent.

\section{Increasing length and complexity}

Another characteristic noted frequently in childhood verbal apraxia is increasing difficulty as words, phrases and sentences get longer or less familiar. Four questions addressed length and complexity with the following results:

\begin{tabular}{|l|l|l|l|l|}
\hline Question: & always & frequently & sometimes & never \\
\hline $\begin{array}{l}\text { My child is } \\
\text { understandable } \\
\text { when he/she says } \\
\text { single words, but has } \\
\text { greater difficulty in } \\
\text { conversation }\end{array}$ & $32.0 \%$ & $33.9 \%$ & $24.7 \%$ & $6.6 \%$ \\
\hline $\begin{array}{l}\text { My child has more } \\
\text { difficulty saying } \\
\text { longer words than } \\
\text { shorter words }\end{array}$ & $34.8 \%$ & $29.8 \%$ & $26.4 \%$ & $7.3 \%$ \\
\hline $\begin{array}{l}\text { My child has more } \\
\text { difficulty speaking } \\
\text { when he/she is using } \\
\text { longer phrases or } \\
\text { sentences }\end{array}$ & $43.7 \%$ & $28.9 \%$ & $18.4 \%$ & $6.3 \%$ \\
\hline $\begin{array}{l}\text { My child's speech is } \\
\text { easier to understand } \\
\text { when he/she is saying } \\
\text { familiar words }\end{array}$ & $47.0 \%$ & $33.5 \%$ & $13.1 \%$ & $4.8 \%$ \\
\hline
\end{tabular}

The responses demonstrated that most children with Down syndrome have increasing difficulty with increasing length of words, phrases, sentences and conversation.

\section{Consonant and vowel production}

Most studies addressing characteristics of childhood verbal apraxia cite difficulties at the sound level on consonants and on vowels, as compared to children with articulation problems, who rarely make errors on vowel sounds. Children with childhood verbal apraxia generally have a limited rep- ertoire of sounds, i.e. they used fewer different sounds in their speech. Difficulties at the syllable level with sound and syllable reversals are often noted in the research literature. Six questions addressed errors at the sound and syllable level with the following results:

\begin{tabular}{|l|l|l|l|l|}
\hline Question: & always & frequently & sometimes & never \\
\hline $\begin{array}{l}\text { My child has } \\
\text { difficulty saying some } \\
\text { consonant sounds }\end{array}$ & $28.9 \%$ & $35.8 \%$ & $28.9 \%$ & $6.0 \%$ \\
\hline $\begin{array}{l}\text { My child has difficulty } \\
\text { saying some vowel } \\
\text { sounds }\end{array}$ & $16.8 \%$ & $25.6 \%$ & $38.4 \%$ & $18.2 \%$ \\
\hline $\begin{array}{l}\text { My child often } \\
\text { reverses sounds in } \\
\text { words (e.g. aminal } \\
\text { for animal) }\end{array}$ & $7.2 \%$ & $23.0 \%$ & $37.3 \%$ & $29.5 \%$ \\
\hline $\begin{array}{l}\text { My child leaves out } \\
\text { sounds in words }\end{array}$ & $16.7 \%$ & $39.7 \%$ & $32.4 \%$ & $9.3 \%$ \\
\hline $\begin{array}{l}\text { My child leaves out } \\
\text { syllables in words }\end{array}$ & $14.6 \%$ & $36.0 \%$ & $34.8 \%$ & $12.3 \%$ \\
\hline $\begin{array}{l}\text { My child uses a few } \\
\text { sounds, but he does } \\
\text { not make many } \\
\text { different sounds }\end{array}$ & $7.3 \%$ & $13.5 \%$ & $27.4 \%$ & $50 \%$ \\
\hline
\end{tabular}

The children with Down syndrome in the survey had difficulty with both consonant and vowel sounds. They had omissions of sounds and syllables. About $30 \%$ of parents reported that their child never had sound reversals, while about $60 \%$ indicated that their child had sound reversals frequently or sometimes.

\section{Imitation skills}

Difficulty with imitation is a clinical sign in childhood verbal apraxia. One question addressed this area with the following result:

\begin{tabular}{|l|l|l|l|l|}
\hline Question: & always & frequently & sometimes & never \\
\hline $\begin{array}{l}\text { It is hard for my child } \\
\text { to imitate a word } \\
\text { that I say }\end{array}$ & $11.7 \%$ & $23.8 \%$ & $50.7 \%$ & $13.3 \%$ \\
\hline
\end{tabular}

Thus, parents reported that imitation of words was difficult for their children with Down syndrome.

\section{Prosody and rhythm}

Difficulty with prosody and the rhythm of speech, including prolongations and difficulties with stress is noted in the research literature as occurring with childhood verbal apraxia. Two questions addressed that area with the following results:

\begin{tabular}{|l|l|l|l|l|}
\hline Question: & always & frequently & sometimes & never \\
\hline $\begin{array}{l}\text { My child speaks } \\
\text { rapidly }\end{array}$ & $11.2 \%$ & $25.8 \%$ & $34.3 \%$ & $26.5 \%$ \\
\hline $\begin{array}{l}\text { My child prolongs } \\
\text { vowel sounds }\end{array}$ & $6.5 \%$ & $18.5 \%$ & $37.0 \%$ & $35.3 \%$ \\
\hline
\end{tabular}


Parents reported that about $3 / 4$ of children with Down syndrome had difficulty with rapid rate of speech and about $2 / 3$ had vowel prolongations at least some of the time.

\section{Struggle when speaking}

Struggle and groping for sounds is noted in the childhood verbal apraxia literature. One question addressed that area with the following results:

\begin{tabular}{|l|l|l|l|l|}
\hline Question: & always & frequently & sometimes & never \\
\hline $\begin{array}{l}\text { My child seems to } \\
\text { be struggling so hard } \\
\text { to say words and } \\
\text { sounds }\end{array}$ & $21.1 \%$ & $26.6 \%$ & $35.7 \%$ & $14.9 \%$ \\
\hline
\end{tabular}

Some $85 \%$ of children were struggling hard to say words sometimes, frequently or always.

\section{Relationship between age of first word and apraxia}

Children with Down syndrome who have been given a diagnosis of apraxia begin speaking at a later age, mean of 5 years of age. A 2 tailed Pearson correlation for age of first word and intelligibility rating was significant beyond the .01 level (significance $>.01$ ). Children who began to speak after age 5 had lower parental intelligibility ratings.

\section{Relationship between speech intelligibility and apraxia}

Children who have diagnosis of childhood verbal apraxia have lower intelligibility scores. A 2 tailed Pearson correlation was significant beyond the .01 level. (significance $>.01)$

Occurrence of the symptoms of apraxia is correlated highly with difficulty in speaking. See Table 5 for the results.

\section{Diagnostic label of difficulty with oral motor skills or childhood verbal apraxia}

Survey results indicated that $47.1 \%$ of children have been diagnosed with oral motor difficulties, $2 \%$ with childhood verbal apraxia, $13.1 \%$ with both oral motor and apraxia difficulties, and $37.5 \%$ with neither. Thus, $60.2 \%$ have been given the diagnosis of oral motor difficulties and $15.1 \%$ have been given the diagnosis of childhood verbal apraxia. It is rare $(2 \%)$ for parents to be told that their child has apraxia without also being given the diagnosis of oral motor difficulties (both diagnoses-13.1\%). See Table 6 for a diagnostic label summary.
A one-way ANOVA (diagnostic groups x speech intelligibility) was performed and was significant beyond the .01 level. See Table 7 for analysis results. A Tukey-b post hoc test indicated that those with both diagnoses, OM and CVA, had significantly lower speech intelligibility ratings than those with neither disorder. All other diagnostic group comparisons were statistically insignificant.

\section{Relationship between intelligibility rating and diagnostic labels}

Results indicate that children who have diagnoses of childhood verbal apraxia and oral motor difficulties have more difficulty with speech intelligibility (lower intelligibility). Children with Down syndrome who have difficulties with oral motor skills but do not have childhood verbal apraxia do not have lower speech intelligibility ratings. Children who have neither diagnosis have higher intelligibility scores. This was based on 1503 responses.

\section{Conclusions}

(1) The survey found that characteristic symptoms of childhood verbal apraxia (motor planning disorders) are present in individuals with Down syndrome.

(2) Parents could identify characteristic symptoms of childhood verbal apraxia in their children with Down syndrome through using a questionnaire survey.

(3) Childhood verbal apraxia is being underdiagnosed in children with Down syndrome. Only $15.1 \%$ of parents have been given a diagnosis of childhood verbal apraxia. Many more children show characteristics of childhood verbal apraxia in their speech.

(4) Individuals with Down syndrome who display characteristics of childhood verbal apraxia began speaking at a later age. Children who began to speak after age 5 had lower parental intelligibility ratings.

(5) Individuals with Down syndrome who displayed characteristics of childhood verbal apraxia had higher levels of unintelligible speech, i.e. they are more difficult to understand (speech intelligibility problems) than other children with Down syndrome. Occurrence of the symptoms of apraxia is correlated highly with difficulty in speaking.

(6) Results indicate that children who have diagnoses of apraxia and oral motor difficulties have more difficulty with speech intelligibility (lower intelligibility). Children who have a diagnosis of oral motor skills only do not have lower intelligibility scores. Children who have neither diagnosis have higher intelligibility scores.

\begin{tabular}{|lc|}
\hline Diagnosis & Percent \\
Oral motor difficulties & 47.1 \\
Childhood verbal apraxia & 2.0 \\
Both OM and CVA & 13.1 \\
Neither label & 37.5 \\
\hline
\end{tabular}

Table 6. Current diagnostic labels

\begin{tabular}{|lccccc|}
\hline Between groups & SS & df & MS & F & Sig \\
& 2667.493 & 3 & 955.831 & 20.724 & .0001 \\
Within groups & 69181.632 & 1500 & 46.121 & & \\
Total & 72049.125 & 1503 & & & \\
\hline
\end{tabular}

Table 7. ANOVA Analysis 


\section{Discussion}

Most children learn the sounds for speech by listening to and watching adults and other children around them. In children with childhood verbal apraxia, however, the skills needed to program and sequence the movements for speech must be taught and practiced deliberately and often. Because most clinical tests for apraxia involve analysing a child's speech output and rely on a 50-100 utterance sample, using current instruments results in diagnoses of apraxia made in later childhood or early adolescence in children with Down syndrome. Since treatment for apraxia needs to start early, during the period when the young child is learning to make sounds, it is important to find other ways of identifying apraxia. The current study examined whether it is possible to use a parent survey to identify speech characteristics in children with Down syndrome. Based on the results of the survey, it appears that it is possible to use a parent survey as a screening tool. Future research should compare the results of a parent survey with the results of a clinical evaluation for childhood verbal apraxia in children with Down syndrome to determine whether the survey is an accurate, adequate and appropriate measure. Questions on the survey need to be clearly stated. There were some inconsistencies noted in survey results. For example, the literature documents that inconsistency of speech production occurs in children with apraxia. When examples were provided, the survey demonstrated this inconsistency, but when parents were asked whether their child's speech errors were consistent, they responded that they were consistent. If we add the always, frequently and sometimes responses, $79.3 \%$ of the parents responding reported that their child has difficulty saying a word the same way each time, yet the statement, "My child's speech errors are consistent" yielded different results. The author believes that parents interpreted this question as my child consistently makes many errors, rather than as my child makes the same errors. The question can be phrased differently to make it clearer.

The literature and clinical evaluations find a high incidence of hearing loss in children with Down syndrome; some studies as high as $75 \%$. One question on the survey asked parents if the child has difficulty hearing. The results were that $52.6 \%$ of parents reported that their child never had difficulty hearing, $30.5 \%$ sometimes, $10.4 \%$ frequently and $6.1 \%$ always. It may be that this type of information is not appropriate for a survey, or that further questions need to be asked, e.g. does your child have a history of fluid in the ears (glue ear)? Does your child wear hearing aids? Is your child on prophylactic antibiotic therapy? Did your child have p-e tubes implanted?

Analysis of survey responses indicated that very few families of children with Down syndrome are being told that their child has childhood verbal apraxia or similar diagnosis. Only 15\% of the over 1600 families had been given a diagnosis of childhood verbal apraxia by the speech language pathologist or physician although analysis of the survey results demonstrated that the characteristics of childhood verbal apraxia were evidenced in the speech of a majority of the children with Down syndrome. It was very rare for childhood verbal apraxia to be the sole speech diagnosis, i.e. childhood verbal apraxia was found to co-occur with oral motor skill difficulty in $98 \%$ of the children. This finding may indicate that the centres that are diagnosing apraxia are the ones that are alert to signs of both disorders, or it may indicate that both conditions are co-occurring. One possibility that would suggest co-occurrence is that the motor templates needed for speech which are typically developed through vocal play, are not being developed because of the low muscle tone and oral motor difficulties, thus leading to motor planning difficulties. Another theory is that the speech perception and speech production centers in the brain are not communicating well in individuals with Down syndrome. According to analysis of the survey results, many more children with Down syndrome show symptoms of childhood verbal apraxia than are currently being identified. As a result, children with Down syndrome are also not being treated for these difficulties. This finding warrants further investigation.

Although most children learn the sounds for speech by listening to and watching adults and other children around them and practice these sounds through verbal play, this is not true for children with childhood verbal apraxia. In children with childhood verbal apraxia, the skills needed to program and sequence the movements for speech must be taught and practised deliberately and often. Speech-language pathology treatment can focus on providing verbal practice and in partnership with families, an intensive home practice program can be developed. Since childhood verbal apraxia was found to co-occur with oral motor difficulties in all but $2 \%$ of the children, it is possible that early oral motor therapy will help develop the sound templates in the brain to lay the foundation to enable children to program and sequence the sounds. Early oral motor treatment can begin as part of feeding therapy, within the first 3 months of life (Kumin \& Bahr, 1999; Pinder \& Faherty, 1999). It can progress to using straws, horns, whistles, and musical instruments to help develop and practice oral motor skills (Oetter \& Faherty, 1999; Rosenfeld-Johnson, 1999). If treatment begins later, therapy for childhood verbal apraxia will focus on teaching the child to produce each speech sound using visual-tactile cues, and providing daily home practice (Chappell, 1973; Kumin, 1999, 2002b, 2003b; Rosin \& Swift, 1999, Square, 1999; Strand \& Skinner, 1999; Velleman, 2003). The time for beginning this type of therapy will depend on when the child has the neurological maturity and motor skills to be able to imitate and produce the oral motor movements for speech sounds. Many children are able to participate in this type of treatment program by $3-4$ years of age.

Childhood verbal apraxia results in lower speech intelligibility. There is no definitive test for childhood verbal apraxia, at this time. It cannot be diagnosed by a blood test, CT scan, or other medical diagnostic procedure. Current evaluation instruments are descriptive and rely heavily on analysing the child's speech and sound imitation skills. By the time that the diagnosis is made, children with Down 
syndrome are often in middle childhood or adolescence. At that point, valuable time has been lost for treatment and the child has been struggling or using incorrect oral motor sequencing strategies for years. Childhood verbal apraxia can also be identified by the clinical symptom characteristics exhibited in the child's speech and language development, as well as their speech output. This approach can result in earlier identification of the problem. The present study investigated whether characteristics of childhood verbal apraxia can be identified in children with Down syndrome who are experiencing difficulty with speech intelligibility through using a parent survey, and found that parents could identify the symptoms. This finding suggests that a survey form can be developed that could serve as a screening tool. A checklist of speech characteristics can be developed that would help identify childhood verbal apraxia in children with Down syndrome at an earlier age, so that appropriate treatment methods can be used. Survey findings, e.g. lower speech intelligibility ratings and a later age of beginning speech, can be used to develop the checklist. Ten years ago, oral motor skills were rarely identified and treated in children with Down syndrome. Survey results document that oral motor skills are currently being identified in over $60 \%$ of children with Down syndrome. It is time to develop instruments to identify childhood verbal apraxia in individuals with Down syndrome so that appropriate treatment methods can be used. The goal is to help children with Down syndrome develop speech and to improve their speech intelligibility.

\section{Acknowledgements}

Thanks to the Aaron Straus and Lillie Straus Foundation for their grant support and to Dr. Ralph Piedmont for assistance with statistics.

\section{Correspondence}

Libby Kumin - Loyola College in Maryland, Department of Speech-Language Pathology, 450 I North Charles Street, Baltimore, MD 21210-2699 • Fax: 410-997-8735 •E-mail: lkumin@loyola.edu

\section{References}

Buckley, S. (2000). Speech and language development for individuals with Down syndrome - An overview. Portsmouth,UK: The Down Syndrome Educational Trust.

Camaioni, L., Castelli, M.C., Longobardi, E. \& Volterra, V. (1991). A parent report instrument for early language assessment. First Language, 11, 345-359.

Caruso, A.J. \& Strand, E.A. (1999). Motor speech disorders in children: Definitions, background, and a theoretical framework. In A.J. Caruso and E.A. Strand (Eds.), Clinical Management of Motor Speech Disorders in Children. (pp. 1-28). New York: Thieme.

Chamberlain, C.E. \& Strode, R.M. (1999). The source for Down syndrome. E. Moline, IL: LinguiSystems.

Chapman, R. \& Hesketh, L. (2000). Behavioral phenotype of individuals with Down syndrome. Mental Retarda- tion and Developmental Disabilities Research Reviews, 6, 84-95.

Chapman, R., Seung, J., Schwartz, S. \& Bird, E.R. (1998). Language skills of children and adolescents with Down syndrome II: Production deficits. Journal of Speech, Language and Hearing Research, 41, 861-873.

Chappell, G.E. (1973). Childhood verbal apraxia and its treatment. Journal of Speech and Hearing Disorders, 38 (3), 362-368.

Coplan, J. \& Gleason, J.R. (1988). Unclear speech: Recognition and significance of unintelligible speech in preschool children, Pediatrics, 82, 447-452.

Dale, P.S. (1991). The validity of a parent report measure of vocabulary and syntax at 24 months. Journal of Speech and Hearing Research, 34, 565-571.

Davis, B.L., Jakielski, K.J. \& Marquardt, T.P. (1998). Developmental apraxia of speech: Determiners of differential diagnosis. Clinical Linguistics and Phonetics, 12, 25-45.

Edwards, M. (1973). Developmental verbal dyspraxia. British Journal of Disorders of Communication, 8, 64-70.

Elliott, D., Weeks, D.J. \& Elliott, C.L. (1987). Cerebral specialization in individuals with Down's syndrome. American Journal on Mental Retardation, 92, 263-271.

Forrest, K. (2003). Diagnostic criteria of developmental apraxia of speech used by clinical speech-language pathologists. American Journal of Speech-language Pathology, 12, 376-380.

Hall, P.K., Jordan, L.S. \& Robin, D.A. (1993). Developmental Apraxia of Speech. Austin, TX: Pro-Ed.

Hesselwood, B., Bray, M. \& Crookston, I. (1994). Juncture, rhythm, and planning in the speech of an adult with Down's syndrome. Clinical Linguistics and Phonetics, 9, 121-137.

Hickman, L. (1997). The Apraxia Profile: The Descriptive Assessment Tool for Children. San Antonio, TX: Communication Skill Builders.

Horstmeier, D. (1988). But I Don't Understand You - The Communication Interaction of Youths and Adults with Down Syndrome. In Pueschel, S. The Young Person with Down Syndrome. Baltimore: Paul Brookes Publishers.

Kent, R. D., Miolo, G. and Bloedel, S. (1994). The intelligibility of children's speech: A review of evaluation procedures. American Journal of Speech-Language Pathology, 3, 81-95.

Kumin, L. Mental retardation. In L. Schoenbrodt (Ed.) (2004). Childhood communication disorders: Organic bases. Clifton Park, NY: Thomson/Delmar Learning (151-186).

Kumin, L. (2003a). Early Communication Skills in Children with Down Syndrome: A Guide for Parents and Professionals. Bethesda, MD: Woodbine House.

Kumin, L. (2003b). You said it just yesterday, Why not now? Developmental Apraxia of speech in children and adults with Down syndrome. Disability Solutions, 5(2), 1-15.

Kumin, L. (2002a). Why can't you understand what I am saying: Speech intelligibility in Daily Life. Disability Solutions, 5,1-15.

Kumin, L. (2002b). Maximizing speech and language in children and adolescents with Down syndrome. In Cohen, W., Nadel, L. \& Madnick, M. (Eds). Down syndrome: Visions for the 21st century (403-415). NY: Wiley-Liss. 
Kumin, L. (2001). Speech intelligibility in individuals with Down syndrome: A framework for targeting specific factors for assessment and treatment. Down Syndrome Quarterly, 6, 1-8.

Kumin, L. (1999). Comprehensive speech and language treatment for infants, toddlers, and children with Down syndrome. In Hassold, T. J. Down syndrome: A promising future, together. New York, NY: Wiley-Liss, pp. 145-153.

Kumin, L. (1994). Intelligibility of speech in children with Down syndrome in natural settings: Parents' perspective. Perceptual and Motor Skills, 78, 307-313.

Kumin, L. \& Adams, J. (2000). Developmental apraxia of speech and intelligibility in children with Down syndrome. Down Syndrome Quarterly, 5, 1-6.

Kumin, L. \& Bahr, D.C. (1999). Patterns of feeding, eating, and drinking in young children with Down syndrome with oral motor concerns. Down Syndrome Quarterly, 4, 1-8.

Kumin, L., Councill, C. \& Goodman, M. (1998). Expressive vocabulary development in children with Down syndrome. Down Syndrome Quarterly, 3, 1-7.

Lazar, J. (2006). Web usability: A user-centered design approach. Boston: Addison-Wesley.

Lazar, J. \& Preece, J. (2001). Using electronic surveys to evaluate networked resources: From idea to implementation. In C. R. McClure and J. C. Bertot, Evaluating networked information services: techniques, policy and issues. Medford, NJ: Information Today, 137-154.

Lazar, J., Tsao, R. \& Preece, J. (1999). One foot in cyberspace and the other on the ground: A case study of analysis and design issues in a hybrid virtual and physical community. WebNet Journal: Internet technologies, Applications, and Issues, 1(3), 49-57.

Leddy, M. (1999). The biological bases of speech in people with Down syndrome. In J. Miller, M. Leddy \& L.A. Leavitt (Eds.), Improving the communication of people with Down syndrome (pp. 61-80). Baltimore, MD: Paul H. Brookes Publishing Co.

Marcell, M.M. \& Falls, A.L. (2001). Online data collection with special populations over the World Wide Web. Down Syndrome Research and Practice, 7, 106-123.

Miller, J. \& Leddy, M. (1999). Verbal fluency, speech intelligibility, and communicative effectiveness. In J. Miller, M. Leddy and L. A. Leavitt. Improving the communication of people with Down syndrome. Baltimore, MD: Paul H. Brookes.

Miller, J., Leddy, M., Miolo, G. \& Sedey, A. (1995a). The development of early language skills in children with Down syndrome. In Nadel, L. and Rosenthal, D. Down Syndrome: Living and Learning in the Community, New York: Wiley-Liss, 115-119.

Miller, J., Sedey, A. \& Miolo, G. (1995b). Validity of parent report measures of vocabulary development for children with Down syndrome. Journal of Speech and Hearing Research, 38, 1037-1044.

Munson, B., Bjorum, E.M. \& Windsor, J. (2003). Acoustic and perceptual correlates of stress in nonwords produced by children with suspected developmental apraxia of speech and children with phonological disorder. Journal of Speech, Language and Hearing Research, 46, 189-202.

Nijland, L., Maassen, B. \& van der Meulen, S. (2003). Evidence of motor programming deficits in children diagnosed with DAS. Journal of Speech, Language and Hearing Research, 46, 437-450.

Oetter, P., Richter, E.W. \& Frick, S.M. (1995). M.O.R.E.: Integrating the mouth with sensory and postural functions, second edition. Hugo, MN:PDP Press.

Pinder, G.L. \& Faherty, A.S. (1999). Issues in pediatric feeding and swallowing. In A. J. Caruso and E. A. Strand (Eds.), Clinical Management of Motor Speech Disorders in Children. (pp. 281-318). New York: Thieme.

Prichard, C.L., Tekieli, M.E. \& Kozup, J.M. (1979). Developmental apraxia: Diagnostic considerations. Journal of Communication Disorders, 12, 337-348.

Rosenfeld-Johnson, S. (1999). Oral-motor exercises for speech clarity. Tucson, AZ: Innovative Therapists International.

Rosin, P. \& Swift, E. (1999). Communication intervention: Improving the speech intelligibility of children with Down syndrome. In J. Miller, M. Leddy and L. A. Leavitt. Improving the communication of people with Down syndrome. Baltimore, MD: Paul H. Brookes.

Shriberg, L.D., Aram, D.M. \& Kwiatkowski, J. (1997a). Developmental apraxia of speech: I. Descriptive and theoretical perspectives. Journal of Speech, Language, and Hearing Research, 40, 273-285.

Shriberg, L.D., Aram, D.M. \& Kwiatkowski, J. (1997b). Developmental apraxia of speech: II. Toward a diagnostic marker. Journal of Speech, Language, and Hearing Research, 40, 286-312.

Shriberg, L. \& Widder, C.J. (1990). Speech and prosody characteristics of adults with mental retardation, Journal of Speech and Hearing Research, 33,627-653.

Square, P.A. (1999). Treatment of developmental apraxia of speech: Tactile-kinesthetic, rhythmic, and gestural approaches. In A. J. Caruso \& E. A. Strand (Eds.), Clinical Management of Motor Speech Disorders in Children. (pp. 149-186). New York: Thieme.

Stoel-Gammon, C. (2001). Down syndrome phonology: Developmental patterns and intervention strategies. Down Syndrome Research and Practice, 7, 93-100.

Strand, E.A. \& McCauley, R.J. (1999). Assessment procedures for treatment planning in children with phonological and motor speech disorders. In A. J. Caruso \& E. A. Strand (Eds.), Clinical Management of Motor Speech Disorders in Children. (pp.73-108). New York: Thieme.

Strand, A.J. \& Skinner, A. (1999). Treatment of developmental apraxia of speech: Integral stimulation approach. In A. J. Caruso \& E. A. Strand (Eds.), Clinical Management of Motor Speech Disorders in Children. (pp.109148). New York: Thieme.

Swift, E. \& Rosin, P. (1990). A Remediation Sequence to Improve Speech Intelligibility for Students with Down Syndrome. Language, Speech and Hearing Services in Schools, 21, 140-146.

Velleman, S. (2003). Childhood apraxia of speech; resource guide. Clifton Park, NY: Thomson/Delmar Learning.

Weiss, C.E., Gordon, M.E. \& Lillywhite, H.S. (1987). Clinical management of articulatory and phonological disorders. Baltimore, MD: Williams \& Wilkins.

Williams, R., Ingham, R.J. \& Rosenthal, J. (1981). A further analysis for developmental apraxia of speech in children with defective articulation. Journal of Speech and Hearing Research, 24, 496-505. 


\section{Appendix A: Down Syndrome Speech Intelligibility Survey}

\section{Dr. Libby Kumin, Ph.D., CCC-SLP}

We are trying to learn more about the factors that influence whether people can understand your child's speech. It is important to survey a large number of families with children between 1 year and 21 years. The purpose of this survey is to support our efforts at understanding the effectiveness of clinical services. The results will advance our ability to treat speech-related problems. Your answers to this form will be combined with responses from other parents. We hope to share these findings with families and professionals through conference presentations and journal articles. Of course, no names or identifying data will be included in these reports. The few minutes you take to complete this form will be a tremendous help in our efforts to better understand and treat speech-related problems for children with Down syndrome. Working together, we can make a difference.

Thank you for taking the time to complete the survey. Also, please feel free to make copies and distribute to other families through mailings, newsletters and meetings. Complete as many of the questions as you can. We are interested in wide participation, and we need your help!

Today's Date:

Child's Name:

Child's Gender:

Male

$\square$ Female

Child's Birthdate: (Month/Day/Year)

Your Address (optional - if you wish to receive results):

Your E-mail Address (optional):

My child communicates by using (check all that apply):

Speech

Sign Language
Pictures/Photos

Communication Board
High Tech Communication System

Other:

My child began to speak at about $\square \quad 2$ years $\square \quad 3$ years $\square \quad 4$ years $\square \quad 5$ years $\square \quad$ after 5 years

On a scale of 1 to 10, where 1 is completely unintelligible and 10 is completely intelligible, how would you rate your child's speech?

Have you been told that your child has oral motor difficulties?

Have you been told that your child has apraxia or dyspraxia?
Yes

No

Yes

No 
For each question, please check only ONE answer

1. People who know my child well have difficulty understanding his/her speech

2. People who first meet my child have difficulty understanding his/her speech

3. My child communicates primarily by using speech

4. When someone can't understand my child's speech, family members interpret for him or her

5. In infancy, my child made cooing sounds (single sounds)

6. In infancy, my child babbled strings of sounds

7. My child had difficulty sucking and swallowing liquids in infancy

8. My child had feeding difficulties when $s /$ he started eating solid foods

9. My child currently has difficulties with swallowing liquids

10. My child currently has difficulties with feeding/eating

11. My child had low tone in the muscles of the face (lips, tongue, cheeks) in infancy

12. My child currently has low tone in the muscles of the face (lips, tongue, cheeks)

13. My child was late (delayed) in beginning to speak

14. My child makes the same speech errors consistently

15. Sometimes, my child can say a word but at other times, my child has difficulty saying the same word

16. My child is understandable when $\mathrm{s} /$ he says single words, but has greater difficulty in conversation

17. My child uses a few sounds, but does not make many different sounds

18. My child can sing the words in songs more clearly than s/he can say them when speaking

19. My child shows very slow improvement in speech therapy

20. My child seems to be struggling so hard to say words and sounds

always frequently sometimes never

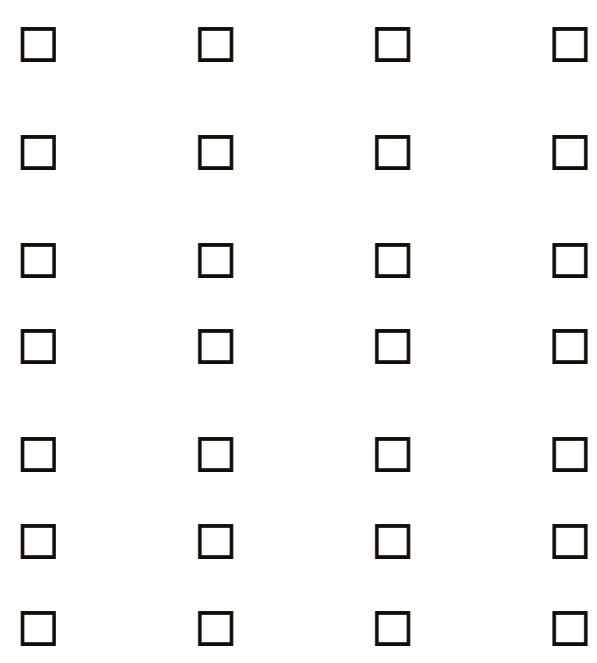

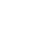


22. My child has fluency (stuttering-like) difficulties when speaking

always frequently sometimes never

23. My child has difficulty hearing

24. My child has more difficulty saying longer words than shorter words

25. My child has more difficulty speaking when $s /$ he is using longer phrases or sentences

26. My child has difficulty saying some consonant sounds

27. My child has difficulty saying some vowel sounds

28. My child often reverses sounds in words (e.g., aminal for animal)

29. My child has difficulty with the rhythm of speech (speech sounds choppy, or sometimes slow and sometimes fast)

30. My child prolongs vowel sounds

31. My child leaves out sounds in words

32. My child leaves out syllables in words

33. My child's speech sounds hypernasal (as if it's coming through his/her nose)

34. My child talks less with people outside of the circle of friends and family

35. It is hard for my child to imitate a word that I say

36. My child's speech is easier to understand when $s /$ he is saying familiar words

37. My child understands more than s/he can say

38. My child may unexpectedly say a word or phrase perfectly, but then s/he can't repeat it

39. My child has difficulty with grammar

40. My child is frustrated when people don't understand what $s /$ he is saying

Comments:

Please return survey to:

Dr. Libby Kumin

Speech Intelligibility Survey, Loyola College, Down Syndrome Center for Excellence, 7135 Minstrel Way, Columbia, MD 21045 